\title{
High pressure crystal chemistry of hydrous ringwoodite and water in the Earth's interior
}

\author{
Joseph R. Smyth ${ }^{\mathrm{a}}$, Christopher M. Holl ${ }^{\mathrm{a}}$, Daniel J. Frost ${ }^{\mathrm{b}}$, Steven D. Jacobsen ${ }^{\mathrm{b}}$ \\ ${ }^{a}$ Department of Geological Sciences, University of Colorado, Boulder, CO 80309 USA \\ ${ }^{b}$ Bayerisches Geoinstitut, Universität Bayreuth, Bayreuth D95440, Germany
}

\begin{abstract}
The crystal chemistry of $\mathrm{Fo}_{90}$ hydrous ringwoodite $\left(\mathrm{Mg}_{1.7} \mathrm{Fe}_{0.22} \mathrm{H}_{0.15} \mathrm{SiO}_{4}\right)$ containing $0.93 \%$ $\mathrm{H}_{2} \mathrm{O}$ by weight has been studied at pressures up to $11.2 \mathrm{GPa}$ by single-crystal X-ray diffraction in the diamond anvil cell. The unit cell edge and volume have been refined at 20 different pressures in this pressure range. The refined bulk modulus for the unit cell is $169.0 \pm 3.4 \mathrm{GPa}$ with a $\mathrm{K}^{\prime}$ of $7.9 \pm 0.9$. $\mathrm{H}$ is accommodated in the structure principally by octahedral cation vacancy. The oxygen position parameter has been refined from X-ray intensity data at ten pressures over this range. With a K' fixed at 4.0, the bulk modulus of the Si tetrahedron is $245 \pm$ $31 \mathrm{GPa}$ and that of the octahedral site is $150 \pm 7 \mathrm{GPa}$. Consistent with a previous study, we observe a systematic decrease of bulk modulus with $\mathrm{H}$ content. From these data, it appears that hydration of ringwoodite has a larger effect on seismic velocity than temperature within the possible ranges of these parameters under upper mantle conditions. This means that in tomographic images of the Transition Zone in regions distant from subduction zones, blue is more likely to mean 'dry' than it is to mean 'cold'. Observed seismic velocities in the Transition Zone are consistent with significant hydration of the ringwoodite $\left(\gamma-(\mathrm{Mg}, \mathrm{Fe})_{2} \mathrm{SiO}_{4}\right)$ structure.
\end{abstract}

Keywords: Ringwoodite, High Pressure, Equation of State, Crystal Structure, Water.

\section{Introduction}

Earth is distinguished from its planetary neighbors by the presence of large amounts of liquid water on its surface. Sea level variation studies indicate that sea level has varied relatively little, but perhaps as much as s few hundred meters, through the Phanerozoic (Duval et al., 1998). The presence of quartz-pebble conglomerates of early Archean age indicates that there has been running water (implying the presence of both oceans and land) nearly as far back as we can see in geologic time. Recent geochemical studies of ancient zircons in Archean sediments by Mojzsis et al. (2001) indicate that there may have been liquid water as far back as $4.3 \mathrm{GY}$ ago. Although the oceans cover $72 \%$ of the surface area, they constitute only $0.025 \%$ of the planet's mass. Silicate minerals of the crust and mantle can incorporate many times this amount of water, so it is possible that these silicates have played a major role in maintaining Earth's oceans over geologic time.
Approximately $65 \%$ of the total mass of the planet is composed of silicate rocks of the mantle and crust in which the only significant anionic species is oxygen. Bulk hydrogen content is perhaps the most poorly constrained compositional variable in the planet, and the total water content of the planet is unknown within an order of magnitude (Drake and Righter, 2002). Olivine, generally believed to be the most abundant mineral phase in the upper $400 \mathrm{~km}$, can incorporate up to 0.2 weight percent $\mathrm{H}_{2} \mathrm{O}$ (Kohlstedt et al., 1996) at $13 \mathrm{GPa}$ and $1100{ }^{\circ} \mathrm{C}$. The maximum water content of pyroxenes is not known, but natural clinopyroxenes have been reported with up to about 0.18 weight percent $\mathrm{H}_{2} \mathrm{O}$ (Rossman and Smyth, 1990; Smyth et al., 1991). In the Transition Zone $(410-660 \mathrm{~km})$, wadsleyite $(\beta$ $\mathrm{Mg}_{2} \mathrm{SiO}_{4}$ ) can incorporate up to about $3.3 \mathrm{wt} \%$ $\mathrm{H}_{2} \mathrm{O}$, (Kohlstedt et al., 1996; Inoue et al., 1995), and ringwoodite $\left(\gamma-\mathrm{Mg}_{2} \mathrm{SiO}_{4}\right)$ has been reported with up to about 2.2 wt\% (Kohlstedt et al., 1996; Kudoh et al., 2000). Thus, if saturated, these nominally anhydrous phases can incorporate at least 
ten times the amount of water in the planet's oceans and may possibly constitute the planet's largest reservoir of water as $\mathrm{H}$ in solid silicates.

In order to test this hypothesis, we have synthesized and characterized single crystals of hydrous high-pressure silicate minerals for measurement of various physical properties. We have synthesized hydrous ringwoodite of likely mantle compositions, and determined the mechanisms of hydration by means of X-ray single crystal diffraction, transmission electron microscopy (TEM) and infrared (IR) spectroscopy (Smyth et al., 2003). The principal hydration mechanism in these samples appears to be octahedral cation vacancy, although there is also a small amount of tetrahedral vacancy. In addition to the X-ray structural characterization, Kleppe et al. (2002) have described the Raman spectra to pressures above $50 \mathrm{GPa}$, and Kavner and Duffy (2001) have studied the deformation strength of several ringwoodites. The crystals are dark blue in color and are too dark for Brillouin spectroscopy, but gigahertz ultrasonic measurements of elastic properties are reported in a companion paper (Jacobsen et al., 2003).

The elastic properties of silicate spinels have been the subject of considerable recent interest. Bulk moduli of natural and synthetic ringwoodites have been measured by powder and single crystal X-ray diffraction, Brillouin spectroscopy and by ultrasonic methods. From synchrotron X-ray powder diffraction to $50 \mathrm{GPa}$ in the diamond anvil cell, Zerr et al. (1993) report a bulk modulus of $183.1 \pm 2.0 \mathrm{GPa}$ with $\mathrm{K}$ ' of $5.4 \pm 0.2$ for a sample of $\mathrm{Fe}_{0.8} \mathrm{Mg}_{1.2} \mathrm{SiO}_{4}$. From single-crystal X-ray diffraction in the diamond cell to more modest pressures (up to $5.5 \mathrm{GPa}$ ), Finger et al. (1977) report a bulk moduli for $\mathrm{Ni}_{2} \mathrm{SiO}_{4}$ and $\mathrm{Fe}_{2} \mathrm{SiO}_{4}$ of $227 \pm 4$ and $196 \pm 4 \mathrm{GPa}$ respectively with $\mathrm{K}^{\prime}$ also fixed to 4.0. These authors also were able to refine the crystal structure at pressure and report atom position parameters for oxygen at several pressures. Hazen (1993) measured the compression of several anhydrous ringwoodites to about $5 \mathrm{GPa},\left(\mathrm{Ni}_{2} \mathrm{SiO}_{4}\right.$, $\mathrm{Mg}_{2} \mathrm{SiO}_{4}, \quad \mathrm{Mg}_{0.8} \mathrm{Fe}_{1.2} \mathrm{SiO}_{4}, \quad \mathrm{Mg}_{0.4} \mathrm{Fe}_{1.6} \mathrm{SiO}_{4}, \quad$ and $\mathrm{Fe}_{2} \mathrm{SiO}_{4}$ ). He reported bulk moduli of $233 \pm 2,184$ $\pm 2,203 \pm 2,205 \pm 2,207 \pm 3 \mathrm{GPa}$, respectively with $\mathrm{K}^{\prime}$ fixed at 4.8 . These data are in good agreement with values of $184 \pm 3 \mathrm{GPa}$, (Weidner et al., 1986) and $226 \pm 2 \mathrm{GPa}$ (Bass et al., 1984) for
$\mathrm{Mg}_{2} \mathrm{SiO}_{4}$ and $\mathrm{Fe}_{2} \mathrm{SiO}_{4}$ respectively by X-ray powder diffraction and Brillouin spectroscopy.

Yusa et al. (2000) report a very sharply reduced bulk modulus of $148 \pm 6 \mathrm{GPa}$ with $\mathrm{K}$ ' of 7.9 for a hydrous, pure- $\mathrm{Mg}$ ringwoodite containing $2.2 \mathrm{wt} \% \mathrm{H}_{2} \mathrm{O}$. So, previous studies indicate an increase of bulk modulus from 184 to 207 for anhydrous compositions from $\mathrm{Mg}_{2} \mathrm{SiO}_{4}$ to $\mathrm{Fe}_{2} \mathrm{SiO}_{4}$ and a dramatic decrease of bulk modulus with hydration. Prior to the work of Kohlstedt et al., (1996) it was not realized that ringwoodite could incorporate significant amounts of hydroxyl, so the material was not routinely analyzed for H. Clearly, hydration will have a much larger effect on velocities and velocity contrasts at 525 and $660 \mathrm{~km}$ than Fe content (Yusa et al., 2000). In order to quantify and refine the effect of hydration on the bulk modulus and crystal structure of ringwoodite at pressure, we have undertaken a study of a $\mathrm{Fo}_{90}$ ringwoodite containing $0.93 \mathrm{wt} \% \mathrm{H}_{2} \mathrm{O}$ by singlecrystal X-ray diffraction in the diamond anvil cell.

\section{Experimental Methods}

\subsection{Synthesis and characterization}

Details of the synthesis and room pressure characterization of the material are reported by Smyth et al., (2003) as their sample number SZ9901. Briefly, the sample was synthesized in the 5000 ton press at the Bayerisches Geoinstitut (BGI) at $20 \mathrm{GPa}$ and $1400^{\circ} \mathrm{C}$. The starting material was a mixture of San Carlos olivine, brucite, quartz, and $\mathrm{FeO}$. The run (heating) duration was approximately five hours. The capsule contained crystals of hydrous ringwoodite up to $800 \mu \mathrm{m}$ in size plus minor amounts of stishovite. The crystals were analyzed by electron microprobe and by IR spectroscopy for $\mathrm{H}_{2} \mathrm{O}$. The composition is approximately $\mathrm{Fo}_{90}$ with $0.93 \mathrm{wt} \% \mathrm{H}_{2} \mathrm{O}$.

\subsection{X-ray diffraction: Unit cell parameters.}

High pressure X-ray diffraction studies on the ringwoodites were preformed on a Siemens/Bruker P4 automated diffractometer with an $18 \mathrm{KW}$ rotating Mo anode source operating at $50 \mathrm{KV}$ and $250 \mathrm{~mA}$. The diffractometer has a graphite-crystal monochromator diffracting in the horizontal plane. This geometry causes the monochromator to induce small shifts in the proportions of the alpha-one and -two peaks included in low-angle diffractions where 
the two wavelengths are not effectively separated as is true for all reflections observed in the diamond anvil cell. This requires that the wavelength of the mixed alpha-one-two peak be calibrated frequently against a known standard. The wavelength of the Mo mixed K-alpha was determined from cell refinement of a standard ruby sphere immediately before and after each cell determination. The unit cell parameters of the ringwoodite and quartz were then determined by refinement from the centering angles of five to eight diffraction peaks in each of eight octants in bisecting mode. Cell parameter precisions determined in this manner are generally better than one part in 10,000 and reproducible to about one part in 5,000.

A single crystal approximately 80 by 60 by 30 $\mu \mathrm{m}$ was loaded in a diamond anvil cell along with a crystal of quartz of similar size and a few small ruby crystals. The pressure medium was a mixture of methanol-ethanol-water at a ratio of 16:3:1. At each pressure the unit cell volumes of the ringwoodite and the quartz were refined as outlined above. The pressure was determined based on the bulk modulus and zero pressure volume of quartz (Angel et al., 1997). The cell parameters of the quartz and ringwoodite at each pressure are reported in Table 1. The error in pressure determination by this method is 0.15 to $0.5 \mathrm{kbar}$ (Table 1) which is considerably less than could be obtained from the ruby fluorescence system which is about $1.0 \mathrm{kbar}$. We therefore used the quartz scale throughout this study. The unit cell volume data of ringwoodite was fit to a third order BurchMurnaghan equation of state using the program EOSFIT42 (Angel, 1999 personal communication). The data give a bulk modulus of $169.0 \pm 3.4 \mathrm{GPa}$ with a $\mathrm{K}^{\prime}$ of $7.9 \pm 0.9$. The individual unit cell volumes and the calculated equation of state are shown in Figure 1.

\section{$2.3 X$-ray diffraction: Intensity data collection.}

At pressures of $0.44,0.76,1.37,2.64,7.11$, $8.60,9.81$, and $11.22 \mathrm{GPa}$, the crystal structure of the ringwoodite was refined from intensity measurements of accessible diffractions. Data were corrected for Lorenz and polarization effects and for absorption of the diamonds using the program DACABS (R.T. Downs, personal communication). Refinements of the structure parameters were done using SHELX97 (Sheldrick, 1997) as contained in

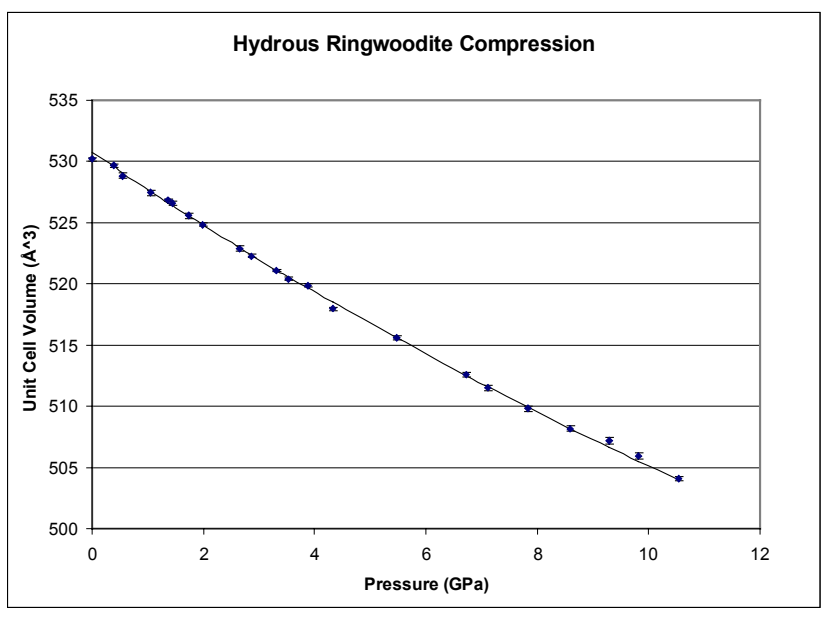

Fig. 1. Unit cell volume of $\mathrm{Fo}_{90}$ hydrous ringwoodite as a function of pressure. Symbols contain error bars. Curve is the fit equation of state with $\mathrm{K}_{0}=169.0 \pm 3.4$ $\mathrm{GPa}$ and $\mathrm{K}^{\prime}=7.9 \pm 0.9$.

the package WinGX. Refinement was done by least-squares minimization of $\mathrm{F}^{2}$. The cation occupancies and atomic displacement parameters were fixed to the room pressure values obtained from a full-octant intensity data set to $90^{\circ} 2 \theta$. By this method only the oxygen position parameter was refined. The site occupancies and displacement parameters were fixed to those given by Smyth et al. (2003). Final position parameter and R(F)-values for structure refinements at each pressure are given in Table 2 along with calculated polyhedral volumes.

\section{Results and Discussion}

\subsection{Polyhedral compression}

There are relatively few high-pressure structure studies of silicate spinels in the literature. Finger et al. (1977, 1979) report structure data for $\mathrm{Fe}_{2} \mathrm{SiO}_{4}$ and $\mathrm{Ni}_{2} \mathrm{SiO}_{4}$ to 4.0 and $5.5 \mathrm{GPa}$ respectively. Finger et al. (1979) give oxygen position parameters at pressures to $5.5 \mathrm{GPa}$ for nickel silicate spinel report a polyhedral bulk modulus of $170 \pm 10 \mathrm{GPa}$ for the octahedron and > $250 \mathrm{GPa}$ for the tetrahedron in $\mathrm{Ni}_{2} \mathrm{SiO}_{4}$ spinel. However, for the $\mathrm{Fe}_{2} \mathrm{SiO}_{4}$, they do not observe significant variation of the oxygen position parameter with pressure and do not report polyhedral bulk moduli. Polyhedral bulk moduli for silicate tetrahedra in orthosilicates range from about 190 to over $550 \mathrm{GPa}$ (Smyth et al., 2000). The Mg octahedron bulk moduli in forsterite range from 100 to $140 \mathrm{GPa}$ (Hazen, 1976; Kudoh and Takéuchi 
Table 1. Unit cell Parameters of hydrous ringwoodite and quartz at various pressures.

\begin{tabular}{|c|c|c|c|c|c|}
\hline \multirow[t]{2}{*}{ Pressure (GPa) } & \multicolumn{3}{|c|}{ Quartz } & \multicolumn{2}{|c|}{ Ringwoodite } \\
\hline & $a(\AA)$ & $c(\AA)$ & $\mathrm{V}\left(A^{3}\right)$ & $a(\AA)$ & $\mathrm{V}\left(A^{3}\right)$ \\
\hline $0.0(0)$ & & & & $8.0936(7)$ & $530.18(14)$ \\
\hline $0.381(14)$ & $4.896(1)$ & $5.389(2)$ & $111.86(4)$ & $8.0909(9)$ & $529.64(17)$ \\
\hline $0.546(18)$ & $4.887(1)$ & $5.386(2)$ & $111.40(5)$ & $8.0868(11)$ & $528.84(22)$ \\
\hline $1.052(15)$ & $4.865(1)$ & $5.370(2)$ & $110.06(4)$ & $8.0796(11)$ & $527.45(22)$ \\
\hline $1.366(12)$ & $4.853(1)$ & $5.358(1)$ & $109.28(5)$ & $8.0766(4)$ & $526.85(9)$ \\
\hline $1.449(21)$ & $4.851(1)$ & $5.352(2)$ & $109.08(5)$ & $8.0752(11)$ & $526.58(21)$ \\
\hline $1.730(22)$ & $4.839(1)$ & $5.346(2)$ & $108.42(5)$ & $8.0701(12)$ & $525.57(25)$ \\
\hline $1.978(17)$ & $4.829(1)$ & $5.338(2)$ & $107.86(4)$ & $8.0664(8)$ & $524.85(15)$ \\
\hline $2.640(24)$ & $4.806(1)$ & $5.322(2)$ & $106.45(5)$ & $8.0564(10)$ & $522.90(19)$ \\
\hline $2.869(15)$ & $4.797(1)$ & $5.322(2)$ & $105.99(3)$ & $8.0531(7)$ & $522.27(14)$ \\
\hline $3.320(16)$ & $4.783(1)$ & $5.306(2)$ & $105.12(3)$ & $8.0471(5)$ & $521.10(11)$ \\
\hline $3.530(16)$ & $4.774(1)$ & $5.307(1)$ & $104.73(3)$ & $8.0435(7)$ & $520.39(13)$ \\
\hline $5.474(26)$ & $4.7166(8)$ & $5.2685(15)$ & $101.50(4)$ & $8.0189(9)$ & $515.63(18)$ \\
\hline $6.714(22)$ & $4.685(1)$ & $5.247(1)$ & $99.73(3)$ & $8.0029(9)$ & $512.56(17)$ \\
\hline $7.105(31)$ & $4.6739(7)$ & $5.2442(10)$ & $99.21(4)$ & $7.9974(11)$ & $511.49(22)$ \\
\hline $7.835(16)$ & $4.6560(5)$ & $5.2351(8)$ & $98.28(2)$ & $7.9886(11)$ & $509.82(21)$ \\
\hline $8.600(34)$ & $4.6391(7)$ & $5.2242(10)$ & $97.32(4)$ & $7.9801(10)$ & $508.19(20)$ \\
\hline $9.283(26)$ & $4.6245(7)$ & $5.2145(9)$ & $96.58(3)$ & 7.9749 (14) & $507.19(27)$ \\
\hline $9.812(28)$ & $4.6125(8)$ & $5.2101(13)$ & $96.00(3)$ & 7.9683 (13) & $505.94(25)$ \\
\hline $10.535(32)$ & $4.5973(7)$ & $5.2032(10)$ & $95.24(4)$ & $7.9584(12)$ & $504.05(24)$ \\
\hline
\end{tabular}

1985), and Fei (1999) reported a value of $160 \pm 2$ $\mathrm{GPa}$ for periclase $(\mathrm{MgO})$.

The polyhedral volume compression of the tetrahedron, octahedron, and the volume of the unit cell not assigned to either polyhedron are plotted in Figure 2. As expected, we observe a stiffer tetrahedron than octahedron. The polyhedral volume data were fit to a third order BirchMurnaghan equation of state. The precision of the data does not permit a significant refinement of $\mathrm{K}$ '.
However, with K' fixed at 4.0, we obtain bulk moduli of $150 \pm 7 \mathrm{GPa}$, and $245 \pm 30 \mathrm{GPa}$ for the octahedron and tetrahedron respectively. With K' fixed to 7.9, the value obtained from the unit cell refinement, we obtain values of $134 \pm 6$, and $228 \pm$ $30 \mathrm{GPa}$. So the octahedral site in this ringwoodite is more somewhat compressible than those in $\mathrm{MgO}$ or $\mathrm{Ni}_{2} \mathrm{SiO}_{4}$ spinel and comparable to the octahedral sites in olivine. The bulk modulus of the tetrahedron is comparable to other silicate

Table 2. Crystal structure parameters of hydrous ringwoodite at various pressures.

\begin{tabular}{|c|c|c|c|c|c|c|c|c|c|}
\hline $\mathrm{P}(\mathrm{GPa})$ & total & obs. & Uniq & $\mathrm{R}(\%)$ & $a(\AA)$ & Xox & Tet.Vol. & Oct.Vol. & $\begin{array}{c}\text { Non-poly. } \\
\text { Vol. }\end{array}$ \\
\hline $0.437(2)$ & 352 & 17 & 13 & 3.81 & $8.0907(6)$ & $0.2438(4)$ & 2.368 & 11.854 & 321.004 \\
\hline $0.763(2)$ & 184 & 18 & 13 & 3.46 & $8.0862(7)$ & $0.2442(2)$ & 2.389 & 11.780 & 321.141 \\
\hline $1.37(2)$ & 184 & 19 & 15 & 3.19 & $8.0766(4)$ & $0.2440(3)$ & 2.369 & 11.762 & 319.704 \\
\hline $2.64(2)$ & 267 & 20 & 15 & 3.28 & $8.0564(10)$ & $0.2442(3)$ & 2.364 & 11.648 & 317.634 \\
\hline 7.11(3) & 301 & 38 & 10 & 3.76 & 7.9974(11) & $0.2446(7)$ & 2.334 & 11.345 & 311.302 \\
\hline $8.60(3)$ & 406 & 32 & 10 & 3.33 & $7.9801(10)$ & $0.2444(6)$ & 2.308 & 11.296 & 308.993 \\
\hline $9.81(3)$ & 408 & 24 & 9 & 2.86 & $7.9683(13)$ & $0.2440(6)$ & 2.296 & 11.249 & 307.578 \\
\hline $11.22(5)$ & 315 & 51 & 13 & 2.49 & $7.9473(10)$ & $0.2448(3)$ & 2.300 & 11.113 & 305.681 \\
\hline
\end{tabular}




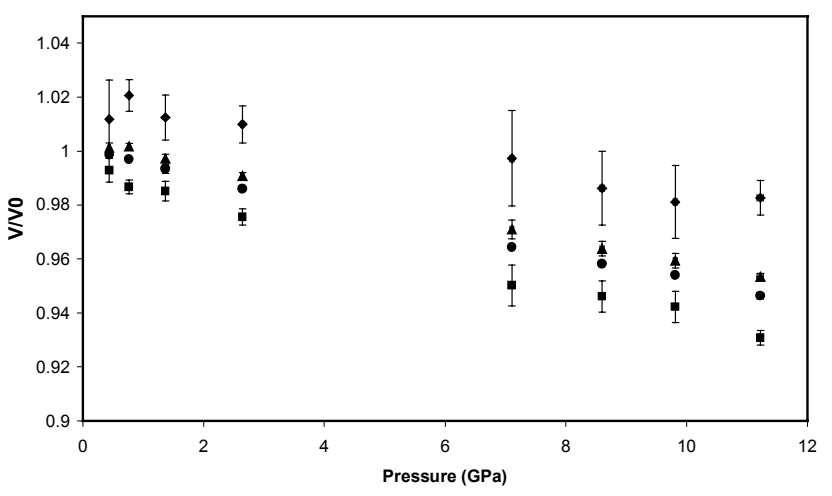

Fig. 2. Relative volume compression of the structural components of hydrous ringwoodite: diamond: tetrahedron; square: octahedron; triangle: nonpolyhedral volume, and circle: cell volume. It is clear that most of the compression takes place in the octahedra.

structures, although there are very few structure refinements in the literature at pressures greater than 6GPa (Smyth et al. 2000). Surprisingly, the non-polyhedral volume is less compressible than the octahedra. The non-polyhedral volume composes approximately sixty percent of the total cell volume in this structure. The large bulk modulus (low compressibility) is probably the result of the near cubic-closest-packing arrangement of the oxygen atoms in the spinel structure (Hazen and Yang, 1999).

\subsection{Equation of State.}

Plotted in Figure 1 are the unit cell volumes as a function of pressure. Also plotted here is the fitted third order Birch-Murnaghan equation of state curve with a $\mathrm{V}_{0}$ of $530.77 \AA, \mathrm{K}_{0}$ of $169.0 \pm 3.4$ and $\mathrm{K}$ ' of $7.9 \pm 0.9$. The error bars plotted in the figure represent the internal precision in the X-ray data, and do not include systematic errors. The pressures were determined from the equation of state of quartz (Angel et al., 1997). The maximum pressure here is slightly above the maximum in the quartz study and we used a simple extrapolation. The slight flexure in the curve above 9 GPa may be due to the extrapolation. It is also possible that the pressure medium may be causing anisotropic strain above about $9 \mathrm{GPa}$. To test this hypothesis, we refined the moduli without the data point above 9 GPa and obtained $\mathrm{K}$ and $\mathrm{K}$ ' value not statistically distinct from those reported above. Hazen (1993) refined a value of $\mathrm{K}$ ' of $6 \pm 2$ for anhydrous ringwoodite. The presence of $\mathrm{H}$ and octahedral cation vacancy in the current structure may account

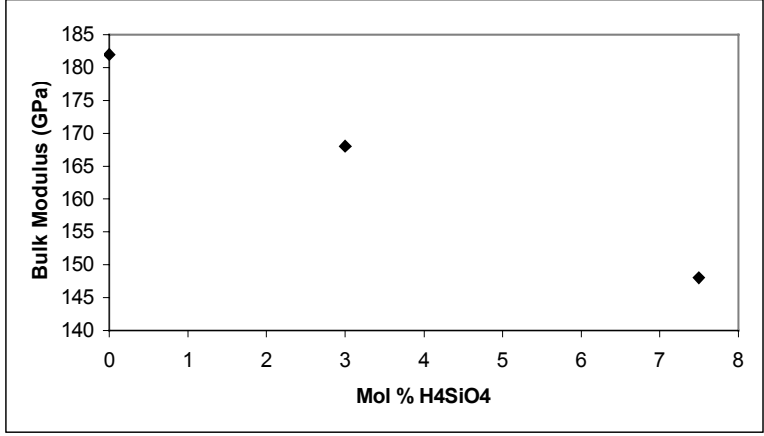

Fig. 3. Bulk modulus vs $\mathrm{H}$ content of ringwoodite. Data for the anhydrous sample is from Hazen (1993) and that most hydrous sample is from Yusa et al. (2000). The cell bulk modulus indicates a linear trend with $\mathrm{H}$ content.

for the relatively large K', but in light of the Hazen (1993) study, the value obtained here is not inconsistent with previous studies. Further study of this material by powder diffraction to higher pressures is in progress.

In Figure 3 is plotted the bulk modulus as a function of hydrogen content for three hydrous and anhydrous ringwoodites. The bulk modulus of anhydrous pure-Mg ringwoodite reported by Hazen (1993) is $182 \pm 2$ and for $\mathrm{Fe}_{2} \mathrm{SiO}_{4}$ is $207 \pm 2$, so one would expect a value of about $184.5 \mathrm{Fo}_{90}$ anhydrous ringwoodite. In a powder-diffraction compression study using synchrotron radiation, Yusa et al. (2000) report a $\mathrm{K}_{0}$ of $148 \mathrm{GPa}$ for a very hydrous ringwoodite with 2.2 weight percent $\mathrm{H}_{2} \mathrm{O}$. The present data are consistent with a near linear trend of bulk modulus with $\mathrm{H}$ content. This variation of bulk modulus with $\mathrm{H}$-content is much larger than the variation with either temperature or Fe content within reasonable ranges of these parameters for the Transition Zone.

\subsection{Relative effects of hydration versus temperature.}

In order to compare the relative effects of temperature and hydration on the bulk modulus we estimated the effective bulk moduli of hydrous and anhydrous ringwoodite at $1200^{\circ} \mathrm{C}$ and $20 \mathrm{GPa}$. To make the estimate we used the $\mathrm{V}_{0}$ values for $\mathrm{Fo}_{100}$ ringwoodite proposed by Smyth et al. (2003) namely $524.1 \AA^{3}$ for anhydrous and $525.3 \AA^{3}$ for $1 \%$ $\mathrm{H}_{2} \mathrm{O}$. We assumed a $\mathrm{K}$ ' of 6 for anhydrous (Hazen, 1993 ) and 7.9 for $1 \% \mathrm{H}_{2} \mathrm{O}$. We assumed a linear thermal expansion coefficient $\left(\alpha_{0}\right)$ of $24.7 \times 10^{-6}{ }^{\circ} \mathrm{C}^{-}$

${ }^{1}$ and an Anderson-Gruneisen parameter, $\delta_{\mathrm{T}}$, of 5.8 
(Meng et al., 1993) for all samples. We then estimated the bulk modulus for the anhydrous sample at $1200{ }^{\circ} \mathrm{C}$ to be about $156 \mathrm{GPa}$, and at 600 ${ }^{\circ} \mathrm{C}$ to be about $170 \mathrm{GPa}$. From these very rough estimates we can see that the effect of hydrating ringwoodite to one weight percent has approximately the same effect on the bulk modulus as raising the temperature by $600{ }^{\circ} \mathrm{C}$. Lateral temperature variation of this magnitude can only be present near subduction zones.

The bulk modulus obtained from static compression measurements is the isothermal bulk modulus, $\mathrm{K}_{\mathrm{T}}$. The adiabatic bulk modulus, $\mathrm{Ks}$, is equal to $K_{T}(1+\alpha \gamma T)$ which is equal to $\rho V_{P}^{2}$., where $\alpha$ is volumetric thermal expansion and $\gamma$, the Grüneisen parameter. The $\alpha \gamma T$ term is relatively small and the $\mathrm{K}_{\mathrm{T}}$ is only slightly smaller than $\mathrm{K}_{\mathrm{S}}$, so it is reasonable to assume that hydration will have a similar effect on $\mathrm{K}_{\mathrm{S}}$ as on $\mathrm{K}_{\mathrm{T}}$. This means that hydration will have a larger effect than temperature on P-velocity, so that in $\mathrm{P}$-wave tomographic images of the Transition Zone in regions distant from subduction zones, blue is more likely to mean 'dry' than it is to mean 'cold'. Conversely, red is more likely to mean 'wet' than 'hot', and inferring lateral thermal anomalies based on velocity variations is, at best, not well constrained. In a companion paper (Jacobsen et al, 2003), we have measured $\mathrm{P}$ and S-velocities in this sample at ambient conditions and obtain a similar result for $\mathrm{P}$ velocities, but it appears that hydration has a larger effect on shear velocity than on P-velocity, so that $\mathrm{V}_{\mathrm{P}} / \mathrm{V}_{\mathrm{S}}$ increases with hydration.

Pyrolite models of mantle composition typically contain more than seventy modal percent olivine, and mantle peridotite xenoliths are typically more than ninety modal percent olivine. However the $\mathrm{P}$ and $\mathrm{S}$ velocities of ringwoodite are too fast relative to PREM (Dziewonski and Anderson, 1981) to have more than about 50 modal percent ringwoodite in the lower part of the Transition Zone (Duffy and Anderson, 1989; Sinogeikin et al., 1998). Inclusion of the hydration variable places the velocities of a nearly pure ringwoodite composition close to those of PREM and weakens possible constraints on the modal proportions of ringwoodite in the lower Transition Zone (525-660 km depth). However, the possibility of hydration may have a significant effect on the depths of the 410 (Smyth and Frost., 2002) and $660 \mathrm{~km}$ depth. Jacobsen et al.,
(2003) have measured a complete set of elastic constants for this material by ultrasonic methods, and report both $\mathrm{P}$ and $\mathrm{S}$ velocities at ambient conditions. They have found an (adiabatic) bulk modulus of $168 \mathrm{GPa}$ in close agreement with the present study. Further study of these interesting samples may be able to provide better constraint on the $\mathrm{P}$ and $\mathrm{S}$ velocities at pressure.

\section{Acknowledgements}

This research was supported the U.S. National Science Foundation grants EAR 00-87279 and EAR 02-29315 and by the Bayerisches Geoinstitut Visitor Program. SDJ was supported by an Alexander von Humboldt Foundation fellowship.

\section{References}

Angel, R.J., Allan, D.R., Miletich, R., \& Finger, L.W., 1997. The use of quartz as an internal pressure standard in high pressure crystallography. J. Appl. Cryst. 30, 461-466.

Bass, J.D., Weidner, D.J., Hamaya, N., Ozima, M., Akimoto, S., 1984. Phys. Chem. Minerals 10, 261-266.

Drake, M. J., Righter, K., 2002. Determining the composition of the Earth. Nature 416, 39-44.

Duval, B.C., Cramez, C., Vail, P. R., 1998. Stratigraphic cycles and major marine source rocks. Mesozoic and Cenozoic Sequence Stratigraphy of European Basins. SEPM Spec. Pub. 60, 43-51.

Duffy, T.S., Anderson, D.L., 1989. Seismic velocities in mantle minerals and the mineralogy of the upper mantle. J. Geophys. Res. 94, 1895-1912.

Dziewonski A. Anderson, D.L., 1981. Preliminary reference Earth model. Phys. Earth. Planet. Int. 25, 297-356.

Fei, Y., 1999. Effects of temperature and composition on the bulk modulus of (Mg,Fe)O. Am. Mineral. 84, 272-276.

Finger, L.W., Hazen, R.M., Yagi, T., 1977. High-pressure crystal structures of spinel polymorphs of $\mathrm{Fe}_{2} \mathrm{SiO}_{4}$ and $\mathrm{Ni}_{2} \mathrm{SiO}_{4}$. Carnegie Inst. Wash Yearb. 76, 504-505.

Finger, L.W., Hazen, R.M., Yagi, T., 1979. Crystal structures and electron densities of nickel and iron silicate spinels at elevated temperature or pressure. Am. Mineral. 64, 10021009.

Hazen, R.M., 1976. Effects of temperature and pressure on the crystal structure of forsterite. Am Mineral 61:1280-1293

Hazen, R.M., 1993. Comparative crystal chemistry of silicate spinels: Anomalous behavior of $(\mathrm{Mg}, \mathrm{Fe})_{2} \mathrm{SiO}_{4}$. Science 259, 206-209.

Hazen, R.M., Yang, H., 1999. Effects of cation substitution and order disorder on P-V-T equations of state of cubic spinels. Am. Mineral. 84, 1956-1960.

Inoue, T., Yurimoto, H., Kudoh, Y., 1995. Hydrous modified spinel, $\mathrm{Mg}_{1.75} \mathrm{SiH}_{0.5} \mathrm{O}_{4}$ : a new water reservoir in the mantle transition region. Geophys. Res. Lett. 22, 117120. 
Jacobsen, S.D., Smyth, J.R., Spetzler, H., 2003. Sound velocities and elasticity of Fe-bearing hydrous ringwoodite. Phys. Earth Planet. Int. This volume

Kavner, A. and Duffy, T.N., 2001. Strength and elasticity of ringwoodite at upper mantle pressures. Geophys. Res. Lett. 28, 2691-2694.

Kleppe, A.K. Jephcoat, A.P., Smyth, J.R., and Frost, D.J., 2002. On protons, iron, and the high pressure behaviour of ringwoodite. Geophys. Res. Lett. (in press).

Kohlstedt, D.L., Keppler, H., Rubie, D.C., 1996. The solubility of water in $\alpha, \beta$ and $\gamma$ phases of $(\mathrm{Mg}, \mathrm{Fe})_{2} \mathrm{SiO}_{4}$. Contrib. Mineral. Petrol. 123, 345-357.

Kudoh, Y., Takéuchi T., 1985. The crystal structure of forsterite $\mathrm{Mg}_{2} \mathrm{SiO}_{4}$ under high pressure up to $149 \mathrm{kbar}$. $\mathrm{Z}$ Krist 117:292-302

Kudoh, Y., Kuribayashi, T., Mizohata, H., Ohtani, E. 2000. Structure and cation disorder of hydrous ringwoodite, $\gamma$ $\mathrm{Mg}_{1.89} \mathrm{Si}_{0.97} \mathrm{H}_{0.34} \mathrm{O}_{4}$. Phys. Chem. Mineral. 27, 474-479.

Meng, Y., Weidner, D.J., Gwanmesia, G.D., Liebermann, R.C., Vaughan, M.T. Wang, Y., Leinenweber, K., Pacalo, R.E., Yeganeh-Haeri, A., and Zhao, Y., 1993. In Situ high P-T $\mathrm{X}$-Ray diffraction studies on three polymorphs $(\alpha, \beta, \gamma)$ of $\mathrm{Mg}_{2} \mathrm{SiO}_{4}$. J. Geophys. Res. 98, 22199-22207.

Mojzsis, S.J., Harrison, T.M., and Pidgeon, R.T., 2001. Oxygen isotope evidenc4e from ancient zircons for liquid water at the Earth's surface 4,300 Myr ago. Nature, 409, 178-181,

Rossman, G.R. and Smyth, J.R., 1990. Hydroxyl and ammonia contents of accessory minerals in mantle eclogites and related rocks. Am. Mineral. 75, 775-780.

Sheldrick G.M., 1997. SHELXL-97 A program for crystal structure refinement. University of Goettingen, Germany, Release 97-2.

Sinogeikin, S.V., Katsura, T. Bass, J.D., 1998. Sound velocities and elastic properties of Fe-bearing wadsleyite and ringwoodite. J. Geophys. Res. 103, 20,919-20825.

Smyth, J.R., Bell, D.R., Rossman, G.R., 1991. Hydrous clinopyroxenes from the upper mantle. Nature, 351, 732735.

Smyth, J.R. Jacobsen, S.D., Hazen, R.M., 2000. Comparative crystal chemistry of the orthosilicate minerals. Rev. Mineral. 41, 187-209.

Smyth J.R., Frost, D.J., 2002. The effect of water on the 410km discontinuity: An experimental study. Geophys. Res. Lett. DOI 2002 GL014418.

Smyth, J.R. Holl, C.M., Frost, D.J., Jacobsen, S.D., Langenhorst, F., McCAmmon, C.A. 2003 Structural systematics of hydrous ringwoodite and water in the Earth's interior. Amer. Mineral (in press).

Weidner, D.J., Sawamoto, H., Sasaki, S., Kumazawa, M., 1986. Single crystal slastic properties of spinel phase of $\mathrm{Mg}_{2} \mathrm{SiO}_{4}$. J. Geophys. Res. 89, 7852-7860.

Yusa, H., Inoue, T., and Ohishi, Y., 2000. Isothermal compressibililty of hydrous ringwoodite and its relation to mantle discontinuities. Geophys. Res. Lett. 27, 413416.

Zerr A., Reichmann, H-J., Euler, H., Boehler, R., 1993. Hydrostatic compression of $\gamma-\left(\mathrm{Mg}_{0.6} \mathrm{Fe}_{0.4}\right)_{2} \mathrm{SiO}_{4}$ to 50.0 
